\title{
Trends in blood lead levels in Christchurch (NZ) and environs $1978-85$
}

\author{
DAPHNE HINTON ${ }^{1}$, PATRICIA A COOPE $^{2}$, WILLIAM A MALPRESS, ${ }^{3}$ AND \\ EDWARD D JANUS ${ }^{1 *}$
}

SUMMARY Blood lead levels have been monitored since 1974 and have shown a significant decrease ( $p<0.001$ ) from 1978 to 1985 in 2830 subjects from Christchurch and environs. From a baseline in August 1978-81 to August 1985 blood lead levels in a population which had no relevant exposure to lead other than that from the general environment have fallen in adult males and females ( $>17$ years) by $42 \%$, and in school and pre-school children $>9$ months by $44 \%$ and $46 \%$ respectively. Reduction of blood lead has accelerated during the last three years. This can be linked to changes in dietary intake and clean up of lead in domestic and industrial environments. Over this decade the lead content of petrol $(0.84 \mathrm{~g} / 1)$ and petrol sales have remained unchanged.

Falling blood lead levels have been reported by us ${ }^{1}$ and throughout the world. For example, the American National Health and Nutrition Examination Survey (NHANES II) data ${ }^{2}$ showed a $36.7 \%$ drop. In their study, findings have been interpreted as primarily due to a reduction of petrol lead. ${ }^{3}$ In contrast, Elwood ${ }^{4}$ noted a $30 \%$ fall in blood leads where petrol lead contribution was not considered a prime factor.

The lead content of petrol $(0.84 \mathrm{~g} / 1)$ and petrol sales have remained constant in our region over the past decade. During this time the mean $\pm 2 S D$ for "usual ranges" established in 1974 required reassessment in 1980,1983 , and 1984 when the proportion of the results below the mean indicated that the "usual range" was too high. Furthermore, figures updated in 1984 for a presentation on the improvements of lead workers' health showed falling lead levels in preemployment screens carried out since May 1979 in a local factory. ${ }^{5}$ Further evidence of falling levels was obtained by analysis of serial blood tests from employees working in low lead exposure occupations. To ascertain if the decline in levels over time was real, "normal subjects" accumulated since 1974 in a computer file were reclassified under date of testing. We present our findings and postulate a link between changes in blood lead and lead in the diet and local environment.

\section{Methods}

POPULATIONS STUDIED

This is a retrospective study of samples analysed by

"Present address: St Vincent's Hospital, Fitzroy, Victoria, Australia. one laboratory from July 1974 to July $1985,95 \%$ of which came from Christchurch and immediate environs. ${ }^{6}$

At intervals from 1974 until the present, results were selected from the routine work to provide a "usual range" for different age groups, sex, and species. Subjects chosen from details supplied were known, or reasoned, to have had no other exposure to lead than that expected from their general living environment. Criteria for selection have remained unchanged over time.

To exclude a possible bias in the annual selection of subjects they were divided into four disparate groups and analysed separately:

1 "Non-service requests"-Up to 10 samples were collected weekly in an unordered pattern at outpatient clinics or staff medicals from consenting children and adults. Name, age, and occupation were recorded. Subjects employed in an occupation, which in our experience ${ }^{6}$ was likely to cause increased lead absorption, were excluded.

2 "Pre-employment screens"-A requirement on previously unexposed males by a lead process factory. ${ }^{5}$

3 "Work-related"-Adults 17 years and over said to be using lead in some form but with "low" blood lead levels and sampled during surveys of:

(a) individuals engaged in specific occupations or hobbies

(b) whole factories.

4 "The remaining subjects" were drawn from:

(a) General practitioner requests for lead levels because of non-specific symptoms, or patient 
concern about possible but unsubstantiated lead exposure.

(b) Local surveys: for example, families following home renovations ${ }^{7}$ where the risk and consequent lead exposure was found to be low.

\section{DATA ANALYSIS}

Each group was examined by year of testing. Because of smaller numbers in 1974-78, the period used for the baseline for change was August 1978 to August 1981. Since there is a variation in "usual blood lead" with sex and age, the data were also considered separately for the following:

(1) males $>17$ years

(2) females $>17$ years

$$
\mathrm{n}=1590
$$

(3) school children 5-16 years

$\mathrm{n}=647$

(4) pre-schol child $n=289$

There was no significant difference between levels found in boys and girls under 17 years.

The distribution of whole blood lead was graphed for each year and was found to have a slight positive skew. As described by Vahter, ${ }^{8}$ geometric means were calculated. However, as $\log$ transformation altered this to a negative skew, it was considered sufficient to report our results as arithmetic means.

\section{ANALYTICAL}

All blood samples were obtained by venepuncture into the same type of Lithium Heparin plastic tube (Disposable Products, Adelaide, South Australia). Carbon furnace atomic absorption was used throughout. ${ }^{5,6}$ From 1976 samples were diluted in Triton X-100.5 There has been a continuity of analytical staff throughout the period.

Comparison of analytical results by specimen exchange with two independent New Zealand laboratories has occurred since 1974 . The laboratory participates in two external quality assessment schemes, ie, UK National External Quality Assessment Scheme (UKNEQAS) Birmingham, since 1976, and a New Zealand Quality Control scheme organised by the National Health Institute (NHI)
Wellington from 1980. The overall performance of our laboratory in both QC schemes has been reliable and consistent. Our results for 135 samples for UKNEQAS throughout the period March 1979-85 were within the acceptability criteria for lead in blood for the Commission of European Communities programme described by Yeoman ${ }^{9}$ but showed a negative bias. However, results for the New Zealand scheme, where samples arrive in better condition, show an equally positive bias in 95 samples from 1980 to 1985 .

Performance at low blood lead levels (0.1-1.2 $\mu \mathrm{mol} / 1$ ) was checked as follows:

(a) April-July 1984 interchange of 41 patient samples with NHI

(b) July 1980-July 1985 interchange of 21 QC samples with NHI, and

(c) July 1979-June 1981 interchange of 6 QC samples with UKNEQAS.

Calculation of regression lines using Demings procedure $^{10}$ for each pair of laboratories gave standard errors about the regression line of (a) 0.07 , (b) 0.06 , (c) 0.08 . This indicates that our analytical variability at low and high blood lead levels is comparable ( $98 \%$ of values lie within $\pm 0.14 \mu \mathrm{mol} / 1$ of the expected value).

\section{Results}

Whole blood lead results are given because they are widely used overseas. However, the annual percentage changes showed almost identical trends when expressed as red cell lead, which is the preferred method of reporting in New Zealand. " Similarly, the annual percentage fall in the arithmetic means was almost identical for geometric means.

Male and female subjects showed minimal variation in age distribution from year to year. Blood lead levels from 1978 to 1985 for adult males and females are given in tables 1 and 2. These show annual arithmetic and geometric mean blood leads and percentage reduction in levels observed after dividing the population into

Table 1 Mean annual levels of whole blood lead (WBL) $\mu$ mol/1 for adult males $>17$ years and overall \% fall in lead levels from a baseline 1978-81 to 1985. Results of disparate groups included for comparison.

\begin{tabular}{|c|c|c|c|c|c|c|c|c|c|c|c|}
\hline \multirow{3}{*}{$\begin{array}{l}\text { Years } \\
\text { from August }\end{array}$} & \multicolumn{2}{|c|}{ Non Service } & \multicolumn{2}{|c|}{ Pre-employment } & \multicolumn{2}{|c|}{ Work related } & \multicolumn{2}{|c|}{ Remainder } & \multicolumn{2}{|c|}{ All males } & \multirow{3}{*}{ Arith } \\
\hline & \multirow[t]{2}{*}{$n$} & \multirow[t]{2}{*}{ Mean $W B L$} & \multirow[t]{2}{*}{$n$} & \multirow[t]{2}{*}{ Mean $W B L$} & \multirow[t]{2}{*}{$n$} & \multirow[t]{2}{*}{ Mean $W B L$} & \multirow[t]{2}{*}{$n$} & \multirow[t]{2}{*}{$\overline{\text { Mean } W B L}$} & \multirow[t]{2}{*}{$n$} & Mean WBL & \\
\hline & & & & & & & & & & Geo & \\
\hline $\begin{array}{l}1978-81 \\
1981-82 \\
1982-83 \\
1983-84 \\
1984-85\end{array}$ & $\begin{array}{r}140 \\
54 \\
41 \\
63 \\
79\end{array}$ & $\begin{array}{l}0.84 \\
0.83 \\
0.72 \\
0.52 \\
0.48\end{array}$ & $\begin{array}{r}106 \\
45 \\
2 \\
19 \\
31\end{array}$ & $\begin{array}{l}0.97 \\
0.90 \\
0.79 \\
0.74 \\
0.58\end{array}$ & $\begin{array}{l}96 \\
44 \\
73 \\
86 \\
62\end{array}$ & $\begin{array}{l}0.78 \\
0.76 \\
0.74 \\
0.59 \\
0.49\end{array}$ & $\begin{array}{r}298 \\
61 \\
106 \\
126 \\
58\end{array}$ & $\begin{array}{l}0.85 \\
0.66 \\
0.70 \\
0.68 \\
0.50\end{array}$ & $\begin{array}{l}640 \\
204 \\
222 \\
294 \\
230\end{array}$ & $\begin{array}{l}0.82 \\
0.75 \\
0.69 \\
0.55 \\
0.47\end{array}$ & $\begin{array}{l}0.86 \\
0.78 \\
0.72 \\
0.58 \\
0.50\end{array}$ \\
\hline $\begin{array}{l}\% \text { Fall from } \\
1978 / 81-85\end{array}$ & & 43 & & 40 & & 37 & & 41 & & 43 & 42 \\
\hline
\end{tabular}


Table 2 Mean annual levels of whole blood lead (WBL) $\mu \mathrm{mol} / 1$ for adult females $>17$ years and overall \% fall in lead levels from a baseline 1978-81 to 1985. Results of disparate groups included.

\begin{tabular}{|c|c|c|c|c|c|c|c|c|c|}
\hline \multirow{3}{*}{$\begin{array}{l}\text { Years } \\
\text { from August }\end{array}$} & \multicolumn{2}{|c|}{ Non Service } & \multicolumn{2}{|c|}{ Work related } & \multicolumn{2}{|c|}{ Remainder } & \multicolumn{2}{|c|}{ All females } & \multirow[b]{3}{*}{ Arith } \\
\hline & \multirow[t]{2}{*}{$n$} & \multirow{2}{*}{$\begin{array}{c}\text { Mean } W B L \\
\bullet\end{array}$} & \multirow[t]{2}{*}{$n$} & \multirow[t]{2}{*}{ Mean $W B L$} & \multirow[t]{2}{*}{$n$} & \multirow[t]{2}{*}{ Mean $W B L$} & \multirow[t]{2}{*}{$n$} & Mean $W B L$ & \\
\hline & & & & & & & & Geo & \\
\hline $1978-81$ & 65 & 0.56 & 31 & 0.56 & 92 & 0.59 & 188 & 0.55 & $0 \cdot 58$ \\
\hline $1981-82$ & 19 & 0.54 & 13 & 0.59 & 37 & 0.52 & 69 & 0.52 & 0.54 \\
\hline $1982-83$ & 28 & 0.47 & 8 & 0.53 & 64 & 0.43 & 100 & 0.42 & 0.45 \\
\hline $1983-84$ & 86 & 0.41 & 10 & 0.48 & 52 & 0.42 & 148 & 0.40 & 0.42 \\
\hline $1984-85$ & 82 & 0.33 & 22 & $0 \cdot 34$ & 38 & 0.32 & 142 & 0.31 & 0.33 \\
\hline \multicolumn{10}{|l|}{$\%$ Fall from } \\
\hline $1978 / 81-85$ & & 41 & & 39 & & 46 & & 44 & 42 \\
\hline
\end{tabular}

disparate groups as described under methods. Analysis of variance showed the homogeneity of these groups with no significant difference at the $5 \%$ level in the trends of blood lead levels. Annual changes were used as the second factor in this analysis and showed, as expected, the decline in blood lead to be highly significant. From the baseline period (1978-81) to August 1985 both adult males and females showed an overall $42 \%$ decrease of blood lead (table 3 ). By 1981-82 (males) and by 1982-83 (females) this decrease was significantly different from zero $(p<0.001)$.

Mean blood lead levels for school children and pre-school children are shown in table 4. There was no appreciable difference in their age distribution over each period of study. Up to August 1985 the school children's blood lead showed a fall of $44 \%$ and the pre-school children $46 \%$ from the baseline years (1978-81) (table 3). This fall was significantly different $(p<0.05)$ for school children by $1982-83$ and by 1981-82 for pre-school children.

Table 3 Summary of annual \% fall in blood lead relative to 1978-81 as a baseline for adult males and females, school and pre-school children

\begin{tabular}{|c|c|c|c|c|}
\hline \multirow{3}{*}{$\begin{array}{l}\text { Years } \\
\text { from August }\end{array}$} & \multicolumn{4}{|c|}{$\%$ Fall $W B L$} \\
\hline & \multicolumn{2}{|l|}{ Adults } & \multicolumn{2}{|c|}{ Children } \\
\hline & Male & Female & School & Pre-School \\
\hline $1978-81$ & $\ldots .$. & ................ & & \\
\hline $1981-82$ & 9 & 5 & 6 & 15 \\
\hline $1982-83$ & 16 & 21 & 12 & 18 \\
\hline $1983-84$ & 33 & 28 & 25 & 29 \\
\hline $1984-85$ & 42 & 42 & 46 & 44 \\
\hline
\end{tabular}

Only 69 infants less than 9 months, without undue lead exposure, were examined over the 1978-85 period. These data were unsuitable for comparative analysis because of the variations in the numbers obtained in each year and the disproportionate numbers of infants in the age spans $<4$ months (average lead $0.26 \mu \mathrm{mol} / 1$ ) and 4 to 8 months (average lead $0.4 \mu \mathrm{mol} / 1$ ). Thus no firm conclusions can be drawn for the trends in blood leads for infants under 9 months whose average value during $1978-85$ was $0.33 \pm 0.30 \mu \mathrm{mol} / 1$.

Mean whole blood lead levels and SEM for males, females, and children are summarised in the figure. Data on 344 subjects before 1978 are shown by broken lines. ${ }^{1}$ The introduction of measures that have considerably reduced dietary lead are also indicated on the time scale. Note that the fall in blood lead is not linear with time but has accelerated since 1982 . However, between August 1976 and July 1985 the annual petrol consumption for Christchurch and immediate environs and the whole North Canterbury region has not varied by more than $8 \%$ (table 5 ).

\section{Discussion}

World-wide interest and many reports concern lead in the environment and its effect on man, including debate about the contribution made by different sources of lead to the amount absorbed. ${ }^{12,13}$ There is nodoubt that blood lead levels of children $>9$ months and adults living in our region have declined since 1974-78.

This is mainly a retrospective study of widely sourced data with a prospective element from late 1983. A well

Table 4 Mean annual levels of whole blood lead (WBL) $\mu$ mol/1 for school children (5-16 years) and pre-school children (9-59 months)

\begin{tabular}{|c|c|c|c|c|c|c|}
\hline \multirow{3}{*}{$\begin{array}{l}\text { Years } \\
\text { from August }\end{array}$} & \multirow{2}{*}{\multicolumn{3}{|c|}{$\frac{\text { School children }}{n}$}} & \multirow{2}{*}{\multicolumn{3}{|c|}{$\frac{\text { Pre-school children }}{n}$}} \\
\hline & & & & & & \\
\hline & $n$ & Geo & Arith & $n$ & Geo & Arith \\
\hline $1978-81$ & 64 & 0.62 & 0.65 & 51 & 0.65 & 0.68 \\
\hline $1981-82$ & 67 & 0.58 & $0 \cdot 61$ & 100 & 0.56 & 0.58 \\
\hline $1982-83$ & 58 & 0.54 & 0.57 & 85 & 0.51 & 0.56 \\
\hline $1983-84$ & 58 & 0.46 & 0.49 & 40 & 0.43 & 0.48 \\
\hline $1984-85$ & 42 & 0.32 & 0.35 & 28 & 0.35 & 0.38 \\
\hline
\end{tabular}


Table 5 Annual petrol consumption from August 1976 to July 1985 for Christchurch and environs and the whole North Canterbury region which includes Christchurch

\begin{tabular}{lll}
\hline & \multicolumn{2}{l}{ Sale of petrol 10 litres } \\
\cline { 2 - 3 } Years & Greater Christchurch & $\begin{array}{l}\text { Christchurch plus } \\
\text { North Canterbury }\end{array}$ \\
\hline August-31 July & & \\
\hline $1976-77$ & 193 & 220 \\
$77-78$ & 200 & 226 \\
$78-79$ & 200 & 218 \\
$79-80$ & $189^{*}$ & $215^{*}$ \\
$80-81$ & 192 & 217 \\
$81-82$ & 206 & 226 \\
$82-83$ & 195 & 222 \\
$83-84$ & 204 & 233 \\
$84-85$ & 196 & 228 \\
\hline
\end{tabular}

*Ban on weekend sale March 79-August 80

Carless days July 79-August 80.

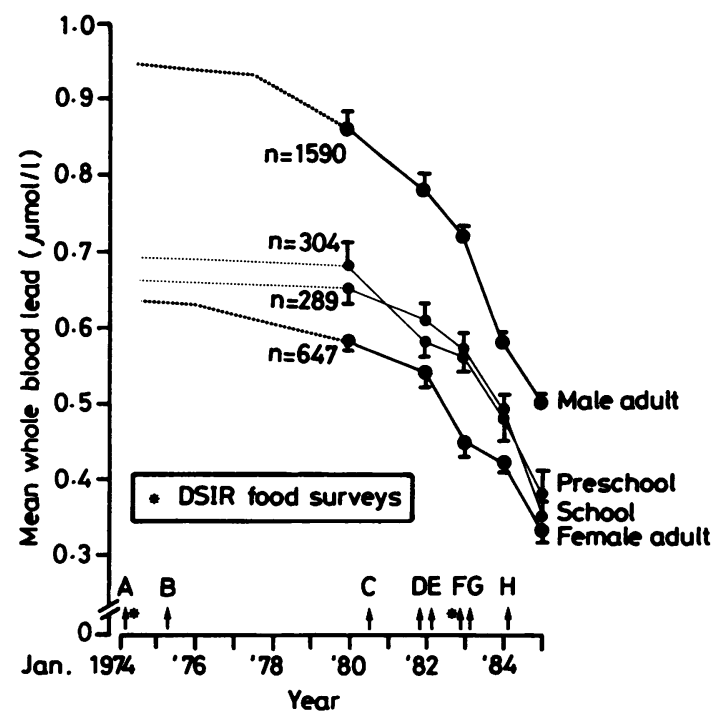

Figure 1 Trends in whole blood lead (umol/1) mean \pm SEM for adult males and females aged 17 years and over, school children (5-16 years), and pre-school children (9-59 months) from 1978 to 1985 . Information on 344 subjects prior to 1978 shown by broken lines. ' Time scale includes reference points to the DSIR food surveys* (lead content of diet falls by approx $24 \%$ ) and approximate dates of sale in the South Island of:

Lead-free solder or pressed seamed cans:
A Baby foods
$B$ Carbonated beverages
$D$ Foods $F$ Fruit juices
C Milk powder $G$ Beer

Laminated foil packets or sachets:

$E$ Fruit juices $H$ Evaporated and dried milk.

balanced range of origin, ages, and subject types drawn from the same area has been maintained each year. The Christchurch region is a discrete area with a stable population of 335000 , approximately $96.8 \%$ Caucasian and $3.2 \%$ Polynesian. The trends noticed in assessments of the "usual range" from service samples have been supported by a concomitant fall in serial tests on the same individuals working where the source of lead is known and absorption is relatively low. Our cumulative method of reporting serial tests on all subjects ${ }^{5,6}$ aids visual appreciation of falling levels over the years.

Laboratory performannce was consistent throughout, with better than average scores in two external quality assessment schemes. Because of the increased technical difficulty in assaying blood lead levels below $0 \cdot 25 \mu \mathrm{mol} / 1$, patient and quality control samples were exchanged with the New Zealand reference laboratory. It is surprising, in view of the worldwide interest in the low levels of lead currently reported in the general population, that over the last eight years only six out of the 200 QC blood samples sent out by UKNEQAS have lead levels $<0.9 \mu \mathrm{mol} / 1$.

All petrol enters by one local port, and accurate reports of petrol sales were available from tax returns from retail outlets for any specified area. These sales have remained remarkably static (table 5). Comparisons with blood leads showed an inverse relationship, indicating that the decline in blood lead levels was not accounted for by petrol sales.

The Christchurch water supply comes from confined and unconfined aquifers. This laboratory has analysed 269 tap water samples for lead from homes in the areas from 1978 to 1985 for patients receiving haemodialysis. When allowed to flow before collection the average water lead is $0.022 \mu \mathrm{mol} / 1$. There has been no change over time. Isolated higher values are occasionally found where the supply is from a private bore or roof. Lead plumbing is not a regional feature.

There has been a systematic lowering of the lead content of the diet, starting in 1974-75 with the introduction of lead-free solder in baby food and carbonated beverage cans. The Department of Scientific and Industrial Research (DSIR) performed two diet surveys, from April 1974 to January 1975, ${ }^{14}$ with a repeat in March to September 1982. Based on consumption by a young adult male, the diets were market basket composites from four major New Zealand cities over four and two seasons respectively. The food was prepared but not cooked. "Results indicate an approximate $24 \%$ drop in dietary lead content and a reduction in canned food consumed from 14 to $8 \%$ " (H V Brewerton, personal communication). This reflects wider use of plastics and freezer packs. In 1981 New Zealand's largest canning suppliers redesigned all but the $A 10$ and 4 litre catering size cans to remove solder completely in favour of seam welding. These cans appeared in South Island retail outlets in 1982. Also in 1981 some natural fruit juices were 
marketed in seven layer laminated foil packs instead of lead solder cans. These new packs were retailed locally from 1982. Lead solder was replaced by Sudronic (resistance) welding for canned fruit juices in 1982 and for locally marketed beer in January 1983. More recently, evaporated milk has appeared in cartons and dried milk in foil-lined sachets. Currently, $20 \%$ of cans are imported, some still with lead solder.

Approximately 50000 Christchurch houses are weatherboard and many of these are or have been painted with high lead paint. This has caused increased lead absorption, particularly in pre-school children and pets. ${ }^{7}$ However, since the introduction of low lead house paints in about 1960 and encouragement of their use, there has been a decline in this source of lead. There is a wider use of timber stains and other low lead sealants. Many old houses have been demolished and new ones constructed with materials that do not require endless coats of paint. Renovations of older homes have seen the replacement of iron roofs with low lead alternatives and wooden door and window frames with aluminium.

There has been a clean-up of local industry, with the introduction from 1979 of efficient emission controlling scrubbers and baghouses. In March 1982 the coal fired gasworks in the centre of Christchurch finally ceased production. Continuous monitoring of air lead about the city gives no relevant data. It reflects seasonal changes and annual variations, ${ }^{15}$ which can be linked in the main to meteorological conditions. Positioning of air lead monitors reflects local vehicle lead emissions rather than those of industry at large.

It is intended to continue annual blood lead observations using similar population sample selection. It is interesting to speculate how much longer the downward trend will continue. Analysing the July 1984-85 figures in two six-month periods suggests that we may have arrived at a plateau for all age groups. Of particular interest now will be the impact in mid-1986 when petrol lead will be reduced to $0.45 \mathrm{~g} / 1$.

We have demonstrated that falling blood lead levels are unrelated to changes in laboratory performance, population sample selection or the lead contribution from petrol or water. It thus appears that for Christchurch the fall in dietary and domestic and industrial environmental sources of lead and increasing public awareness of its effects are the main contributing factors to the observed decrease of blood leads since records began in 1974. Crude data referred to the Department of Health and Princess Margaret Hospital from other parts of New Zealand would appear at this stage to reflect these Christchurch findings.

We thank Deborah Bain and Elizabeth Johnstone for blood lead measurements, and Philip Rodley and Chris Frampton for statistical assistance. We are indebted to:
MrHV Brewerton, DSIR(Chemistry Division), Lower Hutt, for the dietary information, $\mathrm{Mr}$ Errol Hodgkinson (National Health Institute) for blood lead comparisons, Ministry of Energy (Liquid Fuels Section) for petrol sales figures, and various canning companies, the Milk Marketing and Apple and Pear Boards for sales information. We acknowledge the assistance of Medical Illustration Department, Princess Margaret Hospital, Catherine Pawlowski for typing the manuscript, and the Director-General of Health for permission to publish.

Address for correspondence and reprints:

Mrs D Hinton, Pathology Department, The Princess Margaret Hospital, Private Bag, Christchurch, New Zealand

\section{References}

${ }^{1}$ Malpress WA, Janus ED, Hinton D. Blood lead levels in the New Zealand population: A preliminary communication ... NZMJ 1984, 97: 868-9.

2 NHANES II 1976-80. Blood lead levels in the USo population, Morbidity and Mortality Weekly Report 1982 (March 31 132-34).

3 Annest JL, Pirkle JL, et al. Chronological trend in blood? levels between 1976 and 1980. N Eng J Med 1983, 308: 23, 1373-7.

${ }^{4}$ Elwood PC. Changes in blood lead concentrations in $\mathbb{D}$ women in Wales 1972-82. Br med J 1983, 286: 1553-5. $\stackrel{\overparen{D}}{\square}$

${ }^{5}$ Hinton D, Malpress WA, Cresswell BCL, Ussher KE. @ Teamwork can improve the health of lead process workers $\underset{\nabla}{\square}$ NZMJ 1985. 98: 336-339.

${ }^{6}$ Hinton D, Cresswell BCL, Janus ED, Malpress WA Industrial lead exposure-review of blood lead levels in South Island industries 1974-83. NZMJ 1984, 97: 769-73 층

${ }^{7}$ Cameron GC, Malpress WA, Hinton D, Hogan D, Painted houses-sandblasting - a lead hazard. NZMJ 1984, 97:" 121.

${ }^{8}$ Vahter M, Asssessment of human exposure to lead and cadmium through biological monitoring. Stockholm 1982. National Swedish Institute of Environmental Medicine.

${ }^{9}$ Yeoman WB. Internal and external quality control with special reference to lead cadmium. Analytical techniques for heavy metals in biological fluids. Facchetti, S: ELSEVIER, 1983, 273-84.

10 Wakkers PJM, Hellendorn H, OpDeWeegh GJ, Heerspink W. Applications of statistics in clinical chemistry, a critical evaluation of regression lines. Clin Chim Acta 1975, 64: 173-84.

11 Janus ED, Hinton D, Colls BM, Red cell versus whole blood lead. $N Z M J$ 1983, 96: 633-4.

12 Lyman DR, Hughmark GA, Fort BJ Jr, Hall CA. Blood lead concentrations and gasoline lead usage. Proc Heavy Metals in the Environment, Heidelberg September 1983, CEP Consultants Ltd Edinburgh, Vol 1 pp 417-20.

${ }^{13}$ Hammond PB, Bornschein RL, Succop PA, Clark CS. Profiles of lead burdens in early childhood. Proc Heavy Metals in the Environment, Heidelberg September 1983, Vol 1 pp 262-8.

${ }^{14}$ Dick GL, Hughes JT, Mitchell JW, Davidson F. Survey of trace elements and pesticide residues in the NZ diet. $N Z$ Journal of Science 1978, 21: 57-69.

15 Pullen DR, Patterson RN, Air Pollution Survey Christchurch, Annual Reports 1974-81, Department of Health. 